\section{TEMPOS E ESPAÇOS DE GINÁSTICA: SENTIDOS E SENSIBILIDADES QUE SE EDUCAM}

\author{
TIMES AND SPACES OF GYMNASTICS: SENSES AND SENSITIVITIES \\ EDUCATED
}

Diogo Rodrigues Puchta*, Marcus Aurelio Taborda de Oliveira**
Palavras chave: História.

Educação Física. Ginástica.

\section{Keywords:}

History.

Gymnastics.
Physical Education.

\begin{abstract}
Resumo: $O$ artigo tem como objetivo observar prescrições sobre a definição dos espaços e dos tempos para a prática da ginástica nas escolas, no período compreendido entre as três últimas décadas do século XIX e as duas primeiras do século XX. Para a sua escrita, foram mobilizadas diferentes fontes documentais, como programas de ensino, propostas legislativas e manuais de ginástica. A partir das análises foi possível perceber que a escolarização da ginástica representou não apenas a resposta a um novo tipo de sensibilidade, mas a sua produção, como a própria definição de novos valores e costumes na viragem dos oitocentos para o início do século XX.
\end{abstract}

Abstract: This research aims to observe prescriptions about definition of spaces and times for the practice of gymnastics in schools between the last three decades of the 19th century and the first two decades of the 20th century. Various documentary sources were used, such as teaching programs, legislative proposals, and gymnastics manuals. The analysis pointed out that gymnastics schooling was not only a response to a new type of sensitivity but also its production as the very definition of new values and customs at the turn of the 20th century.

Palabras clave: Historia.

Educación Física. Gimnasia.
Resumen: El artículo tiene como objetivo observar prescripciones sobre la definición de los espacios y de los tiempos para la práctica de gimnasia en las escuelas, en el periodo comprendido entre las tres últimas décadas del siglo XIX y las dos primeras del siglo XX. Fueron movilizadas diferentes fuentes documentales, como programas de enseñanza, propuestas legislativas y manuales de gimnasia. A partir de los análisis fue posible percibir que la escolarización de la gimnasia representó no solo la respuesta a un nuevo tipo de sensibilidad, sino la definición de nuevos valores y costumbres a fines del siglo XIX e inicios del XX.
Este trabalho é parte dos resultados do projeto Corpos, natureza e sensibilidades em perspectiva transnacional (entre as décadas finais do século XIX e a década de 1970), desenvolvido junto ao Núcleo de Pesquisas sobre a Educação dos Sentidos e das Sensibilidades (NUPES) na Universidade Federal de Minas Gerais.

*Universidade do Estado de Minas Gerais (UEMG). Belo Horizonte, MG Brasil.

E-mail: diogopuchta@yahoo.com.br

**Universidade Federal de Minas Gerais (UFMG). Belo Horizonte, MG, Brasil. E-mail: marcustaborda@uol.com.br

Recebido em: 13-02-2019

Aprovado em: 24-09-2019

Publicado em: 10-12-2019

DOI

https://doi.org/10.22456/1982-8918.90303

(c) (1) (8) Licence 


\section{INTRODUÇÃOO}

Muito já se historiou sobre o potencial modernizador tanto da escola quanto da ginástica. Ambas representariam a um só tempo a resposta a um novo tipo de sensibilidades, bem como as produziriam no plano da definição de novos costumes estabelecidos como ideais a serem seguidos pelas massas que frequentariam a escola. Estariam inscritas no que, grosso modo, caracterizamos como uma estrutura de sentimentos específica, demarcada temporalmente no período compreendido entre as três últimas décadas do séc. XIX e as duas primeiras do século XX. ${ }^{1}$

Se recuperarmos a premissa que o século XIX foi o século da ciência e, também a partir dela, dos grandes brados pela instrução popular universal e, consequentemente, pela emergente "consciência" da necessidade de educação dos corpos, não temos problemas para aceitar a relação acima enunciada. Ciência, instrução pública universal e educação dos corpos (das quais a ginástica é apenas uma parte) foram signos modernizadores da cultura ocidental. Como tais, a referência a eles abunda em registros materiais diversos, como programas de ensino e propostas legislativas, imprensa periódica, produção literária e livros, entre outros. No caso ao qual nos referiremos, privilegiamos manuais didáticos de ginástica destinados a um amplo leque de potenciais "usuários", com o objetivo de observar prescrições sobre uma dimensão específica da educação dos corpos, a definição dos espaços e dos tempos. Não nos ativemos ao ensino primário ou secundário, mas à prática de ginástica prescrita para as escolas de um modo amplo, uma vez que prescrições sobre tempos e espaços atravessavam a escola independentemente do nível do ensino no qual ela se encontrava.

$O$ processo de seleção das fontes se deu a partir da busca realizada em arquivos físicos de diferentes estados, a saber, São Paulo, Rio de Janeiro, Minas Gerais e Paraná. Neles foram localizados manuais mobilizados para o ensino da ginástica, que não eram os mesmos para cada região, dada a descentralização da educação observada no Brasil no período abordado. Este já é um aspecto que merece atenção dos historiadores, uma vez que não é possível generalizar o uso de determinados manuais na realidade brasileira. Se alguns desses manuais apareciam em diferentes estados, outros eram publicados especificamente em uma localidade. Assim, de posse de um amplo leque de manuais expresso no trabalho de Puchta (2015), optamos por cotejar as prescrições estabelecidas em cada um em relação aos tempos e espaços de ensino da ginástica, tentando compreender aquilo que era comum no período e aquilo que era especifico de uma determinada obra. Em seguida nos debruçamos justamente sobre o que entendemos ser o fundo comum das prescrições no período, uma vez que os manuais que circulavam ou eram produzidos no país se mostraram coetâneos daqueles publicados em outros países. Essa observação nos levou a reafirmar que o processo de modernização da sociedade brasileira se dava em consonância com aquilo que ocorria em outros países no que se refere à educação dos corpos, logo, das sensibilidades.

Mas, ao capturar a prescrição estabelecida pelos manuais em cada realidade estadual, sentimos a necessidade de observar se elas estavam em consonância com os dispositivos legais que norteavam as práticas escolares. Isso nos impeliu à consulta à legislação e aos programas de ensino, também descentralizados. Neles buscamos observar não apenas quando as prescrições dos manuais estavam presentes na norma legal, mas também como

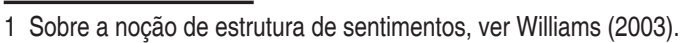


e quando alguns dos livros foram adotados como referência oficial para o ensino. Um caso exemplar é o manual Homem Forte, de Domingos Nascimento. 0 autor absorveu alguns elementos da obra de Schreber para produzir um pequeno opúsculo adequado à realidade no seu estado, o Paraná, tendo sido oficialmente recomendado. No entanto, a sua circulação não transcendeu as fronteiras daquele estado, apesar de uma ou outra referência a ele em outros lugares (PUCHTA, 2019). Mas se foi produzido para uma realidade específica, esse manual não deixa de atestar como saberes, conhecimentos e prescrições circulavam amplamente no período, no que se refere à educação dos corpos, alternando tradição e inovação na sua formulação.

Essa análise, então, permitiu que tratássemos o tema objeto deste artigo em uma perspectiva tanto sincrônica quando diacrônica, lembrando que os tempos escolares, como todos aqueles tempos que não se submetem aos imperativos dos ritmos da natureza, são historicamente contingentes, como bem demonstrou Thompson (1998). Na modernidade são uma expressão mimética de outros tempos sociais, assim como ajudam a defini-los. Aceleração, ritmo, energia, velocidade, movimento, recordes expressam um conjunto de valências que implicariam a educação das vontades, forte motivação para a educação dos corpos, parte da retórica legitimadora da ginástica. Já os espaços escolares contribuiriam para a definição de formas de contenção e enquadramento adequadas aos imperativos pedagógicos e escolares. Afinal, ser e estar no mundo implica a ocupação de espaços em determinados intervalos temporais, o que definitivamente é algo que aprendemos, tenhamos ou não consciência disso.

Se os sentidos podem ser compreendidos como percepções psicofísicas dos fenômenos, então a mobilização dos tempos e dos espaços para a educação dos corpos é um dispositivo educativo de primeira ordem não só na escola, mas prioritariamente ali. Não por acaso o léxico e as práticas da ginástica reproduziram historicamente ad nauseum expressões como rápido, veloz, lento, ritmo, coluna, fila, dentro, fora, sobre, longe, perto, longo, curto, alto, baixo. Mesmo em tempos relativamente recentes essa ênfase se expandiu, por exemplo, com as diversas escolas psicomotoras que propagaram noções como coordenação óculo manual ou pedal, ou orientação espaço-temporal, fosse para a educação ou "reeducação" dos corpos. Assim, além do conjunto de práticas que podem conter, estimular ou definir, os tempos e os espaços são, por si sós, objeto e vetor da educação dos corpos.

No que se refere especificamente à ginástica, devemos recordar que a ampliação dos conhecimentos escolarizados, em decorrência da inserção de novas disciplinas no currículo, encontra-se entre as principais medidas que afetaram a organização da escola com a implantação do modelo graduado de ensino no final dos oitocentos. Em decorrência dessa ampliação do currículo a partir do ensino público primário nota-se a inserção cada vez maior da prática de ginástica nas escolas, sobretudo, mas não só, nos grupos escolares². Daquele quadro de reformas da instrução pública, disseminado pelo mundo ocidental a partir do último quartil do século XIX, gostaríamos de destacar novas formas de organização do tempo e dos espaços escolares. Isso porque estreitas relações podem ser observadas entre as mudanças quanto ao uso do tempo e dos espaços, com a construção de prédios específicos, com o desenvolvimento dos métodos de ensino e, por conseguinte, dos materiais pedagógicos específicos para a escolarização universal (FARIA FILHO; VIDAL, 2000). Para nós está claro que os usos do

2 Taborda de Oliveira (2009) já observou como a ginástica já estava presente nas escolas isoladas do Paraná pelo menos desde a década de 1870. 
tempo e a configuração dos espaços escolares guardam uma forte relação com a educação do corpo dos estudantes, portanto, com a educação dos sentidos e das sensibilidades. ${ }^{3}$

A produção de novas sensibilidades pela exploração dos sentidos estimulados através do uso dos tempos e espaços escolares apresentaria relações com o ensino de diferentes rubricas disciplinares, tais como o Canto, a Educação Artística, as Ciências, as Matemáticas, entre outras presentes tanto na escola primária quanto na secundária. Mas entendemos que a ginástica e, depois, a Educação Física, se destacaram em relação a este particular, sendo marcas tangíveis de uma filosofia da vida de caráter tipicamente moderno. Em vista disso, passamos a nos questionar: o que mudou na organização do tempo, na construção de espaços ou na aquisição de materiais didáticos com a inserção da ginástica no currículo da escola brasileira a partir da década de 1880? Atentos a essa dimensão da educação dos sentidos e das sensibilidades na formação das novas gerações, procuramos observar as possíveis influências dos exercícios físicos em geral, particularmente da ginástica, na redefinição dos tempos e espaços escolares, percorrendo as prescrições para a sua prática no Brasil.

\section{SOBRE TEMPOS}

A prática regular de exercícios físicos nas escolas primárias nos anos finais do século XIX e início do século XX foi, em alguma medida, influenciada pela publicação e circulação de manuais de ginástica (PUCHTA, 2015). Com o nascente mercado das edições escolares que se instituía não apenas no Brasil, observa-se um significativo processo de produção e circulação de prescrições sobre aquelas práticas. Através do contato com os manuais de ginástica era possível ter acesso não só a diversos conhecimentos sobre o corpo humano e o seu funcionamento, mas também a séries de exercícios e programas de ensino nos quais os professores poderiam se basear para organizar as suas aulas. Como as práticas escolares não podem prescindir de definições temporais e espaciais precisas, pela própria racionalidade inerente à instituição escolar, então as prescrições sobre a exercitação dos corpos pela via da ginástica vinham acompanhadas de correspondentes recomendações sobre a melhor forma de produzir ou usar espaços e tempos. Confrontando as prescrições quanto à frequência e duração dos exercícios ginásticos presentes em alguns dos livros por nós estudados, notase a diferença de tratamento dada pelos autores a essa questão, o que reflete pluralidade e diferenças não apenas em como cada autor concebia a ginástica, mas na maneira como operavam com aquela prática.

No manual de Daniel Schreber, por exemplo, 15 ou 30 minutos seguidos de exercícios, quando muito, eram considerados suficientes (SCHREBER, [18--]). No entanto, 0 autor defendia a prática regular dos exercícios uma ou duas vezes por dia. Quanto à presença da ginástica nas escolas, o autor era taxativo: "nenhuma criança deve permanecer assentada e com o espírito aplicado durante mais de duas horas" (SCHREBER, [18--], p. 150). Ao longo

\footnotetext{
3 São inúmeras as contribuições para tratar das relações entre educação do corpo, ginástica e educação das sensibilidades em chave histórica. Não seria possível esgotar nos limites deste texto uma revisão exaustiva sobre essa relação. Contudo, muitos indícios nos são oferecidos pelos trabalhos oriundos da equipe coordenada pela Professora Carmen Lúcia Soares, na Unicamp, além dos grupos de Andrea Moreno e Meily Linhales, na UFMG. A título de exemplo podemos citar o dossiê organizado por Soares e Moreno (2015). Além daquele trabalho, podemos observar significativas reflexões em Moreno (2019), Medeiros e Soares (2017), Quitzau e Soares (2016). Em relação à educação do corpo, além das autoras acima citadas, vale a pena conferir: Taborda de Oliveira e Linhales (2011), além do livro organizado por Taborda de Oliveira (2006). Sobre a educação dos sentidos e das sensibilidades, algumas reflexões, inclusive em dimensão transnacional, estão disponíveis em Taborda de Oliveira (2012) e Braghini, Munakata e Taborda de Oliveira (2017). Balanços mais exaustivos sobre o entrecruzamento dessas temáticas podem ser encontrados em Puchta (2015) e Taborda de Oliveira. Educação dos sentidos e das sensibilidades: mais uma moda acadêmica ou possibilidade de renovação no âmbito das pesquisas em História da Educação Física? No prelo.
} 
dos trabalhos escolares o mesmo autor também recomendava um "intervalo de um quarto de hora à execução de alguns exercícios convenientes" (SCHREBER, [18--], p. 150). Assim, ao ser escolarizada, a ginástica parece ter influenciado a definição e concessão dos intervalos, em função de preocupações sobretudo higiênicas, interferindo, consequentemente, na composição dos horários da instituição escolar como um todo.

Já um autor como Pedro Manuel Borges recomendava a prática da ginástica ao menos duas vezes por semana (BORGES, 1888). Manuais como o publicado por Caldas e Carvalho recomendava quatro seções de uma hora por semana (CALDAS; CARVALHO, 1896). Arthur Higgins, em seu manual, delimitava o tempo de cada aula de acordo com a frequência dos exercícios, ou seja: lições diárias de 30 minutos; três lições por semana de 45 minutos cada; ou uma lição por semana de uma hora de duração (HIGGINS, 1909). Segundo ele, "O tempo que deve durar uma lição de ginástica depende muito das espécies de exercícios que se tenham de ensinar, e do número de lições a dar durante a semana. As lições de ginástica sistemática devem durar menos que as de ginástica de aparelhos e estas menos que as de ginástica recreativa" (HIGGINS, 1909, p. 28).

Essa pluralidade de prescrições quanto à prática da ginástica reflete não apenas a falta de consenso entre os autores, algo difícil de granjear em um momento em que a ciência se confundia com o cientificismo (GAY, 1989), mas uma possível diversidade de experiências, especialmente no caso daqueles autores que também foram professores de ginástica, que já trabalhavam com o ensino da ginástica no seu cotidiano, fosse no ensino primário ou no secundário4. Talvez tenha sido no âmbito daquela experiência que esses autores encontraram os subsídios necessários para definir qual seria o melhor tempo para um determinado exercício e não para outro, mesmo quando reivindicavam um cariz cientificista para as suas práticas.

Um dos horários nos quais mais se reconhecia a pratica dos exercícios ginásticos era durante o recreio, o que denota um momento anterior à disciplinarização dessa prática. Kumlien, ao defender a presença da ginástica nas escolas, também foi um defensor daqueles intervalos na rotina escolar (KUMLIEN, 1908). Segundo ele, a hora/tempo do recreio poderia ser empregada como hora/tempo da ginástica, ou vice-versa. Contudo, Kumlien considerava que os exercícios ginásticos regulares não poderiam jamais ser substituídos por aquele tempo.

Os folguedos a que as crianças e os rapazes se entregam, durante os recreios, são evidentemente úteis, diremos até necessários. Deviam mesmo ser mais frequentes, interromper maior número de vezes as aulas e o estudo, como sucede na Suécia.

Por muito úteis que sejam necessitam, todavia, de serem completados por movimentos metódicos, que façam pôr em movimento as partes do corpo que não tenham tido o preciso exercício durante as horas de recreio. Este não pode de modo nenhum substituir a ginástica, única forma de regularizar o funcionamento normal de todo o organismo (KUMLIEN, 1908, p. 10 e 11, grifos nossos).

O recreio, em tese, seria o momento no qual as crianças poderiam brincar em liberdade. Porém, nota-se aqui uma intenção em tirar da brincadeira, do brinquedo ou do tempo "livre" que caracteriza aquele tempo uma consequência utilitária (MEURER; TABORDA DE OLIVEIRA, 2016). Era importante que as crianças brincassem, pois ao mesmo tempo em que brincavam elas também corriam, pulavam, se movimentavam, enfim, também cuidavam da atividade do corpo.

4 Manoel Baragiola, Pedro Manoel Borges e Arthur Higgins são alguns dos autores que também foram professores de ginástica nas escolas Outros autores de manuais eram médicos ou militares. 
Às brincadeiras do recreio deveriam ser acrescentados os exercícios ginásticos insubstituíveis, segundo o autor, configurando um processo não apenas de prescrição, mas de intervenção clara sobre os usos dos tempos pelas crianças, consequentemente, pelos professores. $\mathrm{Ou}$ seja, a Educação Física da criança como prática pedagógica metódica não nasce com um espírito lúdico, como muito se propalou e ainda se reivindica (VAGO, 1997), ela nasce com um espírito francamente utilitário, com preocupações de restauração das disposições para o trabalho, emolduradas por um discurso de fomento da saúde. Bem observado, a inclusão da ginástica no currículo, quando se tratou da escola, mas também em outras dimensões da vida social, guarda estreita relação com o reconhecimento da importância dos intervalos no desempenho das atividades (escolares ou não).

A necessidade de intervalos estava associada, ainda, ao problema da fadiga intelectual ou surmenage. Essa preocupação levou à definição de um maior número de intervalos entre as atividades escolares, preenchidos muitas vezes com exercícios de marcha na sala de aula. A criação desses intervalos implicou a redefinição dos horários, portanto, a redistribuição ou (re)invenção do tempo da escola. Isso contribuía para a incorporação dos exercícios físicos em geral e da ginástica, em especial, no currículo, da mesma forma que acontecia com o canto ou com outros dispositivos como os recreios (MEURER; TABORDA DE OLIVEIRA, 2016). Essa "concessão" em relação aos tempos destinados à aprendizagem decorria particularmente do reconhecimento dos benefícios dos intervalos na retomada da atenção e da disposição para o trabalho, hipoteticamente influenciando no desempenho dos alunos.

Tais medidas eram provenientes do saber médico relacionado à higiene mental (ou do espírito), em confluência com outros saberes oriundos da psicologia experimental, desenvolvida no final do século XIX, notadamente na Alemanha, França e Suíça (CAMPOS, 2003; CAMPOS; GOUVEA; GUIMARÃES, 2014), mas também da fisiologia do trabalho. Se inicialmente a Educação Física se fundamentou nos conhecimentos produzidos no âmbito da higiene, notase que ela vai se deslocando dentro do conhecimento considerado científico e se aproximando mais da psicologia experimental e da fisiologia, mas sem abandonar as preocupações com a saúde individual e social.

\section{SOBRE ESPAÇOS}

Antes de ser praticada nas escolas, a ginástica já estava presente em outros lugares e instituições como clubes, circos e sociedades de ginástica. ${ }^{5}$ No decorrer do século XIX ela se tornou uma prática social em ascensão, passando a ser praticada também nas escolas, tornando-se, inclusive, prática escolar obrigatória. Contudo, ao adentrar o espaço escolar, onde alocá-la nas escolas ou entre as atividades escolares?

Devemos lembrar que as atividades físicas, incluindo a ginástica e as brincadeiras, já eram estimuladas por alguns professores nos espaços livre contíguos às escolas isoladas, como no caso do professor Durski, no interior do Paraná (TABORDA DE OLIVEIRA, 2009). Também os professores da região da capital paranaense afirmavam desenvolver aquelas práticas no interior dos espaços disponíveis no entorno da escola, ou mesmo na sala de

5 Entre os estudos dedicados à história da ginástica destacamos os trabalhos de Melo e Peres (2014) e Moreno (2015). As práticas de ginástica ministradas por professores no Rio de Janeiro entre escolas, clubes e sociedades foi tema da dissertação recentemente defendida por Anna Luiza Ferreira Romão, em 2016. Em relação à presença da ginástica no circo, ver a dissertação de Pedro Luiz da Costa Cabral, também defendida em 2016. 
aula. Ou seja, eram espaços ainda difusos, não especificamente pensados para aquela finalidade. No caso das salas de aula, na falta de um espaço específico, poderia ser utilizado aquele espaço produzido e privilegiado para as atividades gerais do ensino. O seu uso para a ginástica aparece entre as prescrições presentes no manual assinado por Manoel Baragiola. Ao prescrever a prática da ginástica entre os bancos das salas, ou seja, uma ginástica de "salão", Baragiola aconselhava que "antes de começar os exercícios ginásticos, deve-se deixar renovar o ar das aulas e não se executarão exercícios em corrente de ar" (BARAGIOLA, 1895, p. 17).

Mas a prática de exercícios físicos nas escolas também influenciou na construção dos prédios e na (re)configuração dos espaços escolares. A maneira como os espaços eram organizados, sua configuração interna e externa, a presença ou não de objetos, aparelhos, máquinas, entre outros artefatos criados para a atividade do corpo, nos oferece uma dimensão dos exercícios que poderiam ser realizados e das adaptações que a escola precisava realizar.

Além disso, a ordenação dos espaços também guarda relações com outros aspectos da atividade educativa, como os métodos de ensino. Não é demais relembrar como muitas disciplinas se valiam de algum tipo de prescrição sobre os usos do corpo para desenvolver as suas atividades. Por isso, o espaço pode ser entendido como um elemento significativo do currículo, com forte potência formativa (ESCOLANO, 1993/1994, 2000). Na escola existem espaços onde deve imperar o silêncio ou se pode falar, nos quais se pode correr ou se deve andar devagar, para atividades consideradas sérias ou para atividades de caráter lúdico, de uso comum a todos ou vetados aos alunos etc. Muitos são construídos especificamente para determinados fins, ainda que normalmente os usos deles subvertam os imperativos para os quais foram criados.

Em relação aos espaços destinados à educação do corpo não foi diferente. Primeiramente adaptados àqueles espaços já disponíveis, na medida em que se tornavam mais complexas e se expandiam as suas práticas, a ginástica passava a ser fomentadora até mesmo da construção de espaços específicos, que podem ser ditos especializados, como no caso dos ginásios. Porém, partindo de propostas como a elaborada por Schreber, é preciso reconhecer que um dos espaços que a ginástica deveria ocupar era o próprio ambiente doméstico. Os exercícios ginásticos publicados pelo autor foram pensados justamente para que pudessem ser realizados sem a necessidade de sair de casa.

Mas aqueles eram apenas os primeiros momentos da ginástica no cotidiano da vida escolar. Com a crescente construção e expansão das escolas reunidas e dos grupos escolares pelo país, muitos edifícios passaram a incorporar espaços que consideravam a possibilidade de algum tipo de atividade corporal por parte dos alunos, como mostra o trabalho de Vago (2002). Um dessas inovações era a construção em “U”, bastante explorada por autores como Viñao $(1993 / 1994,1996,2005)$ e Bencostta $(2005,2007)$. Normalmente o espaço entre as duas alas paralelas dos edifícios escolares eram destinados ao recreio dos alunos, o qual, como veremos, poderia incluir exercícios ginásticos. ${ }^{6}$

6 Nos limites deste artigo não temos a pretensão de fazer uma análise detalhada das plantas dos edifícios escolares, pois fugiria ao seu escopo. O seu uso tem um caráter de ilustração em relação ao argumento que, gradativamente, os espaços destinados à ginástica foram institucionalizados. 
Figura 1 - Planta baixa do Grupo Escolar Dr. Xavier da Silva em Curitiba

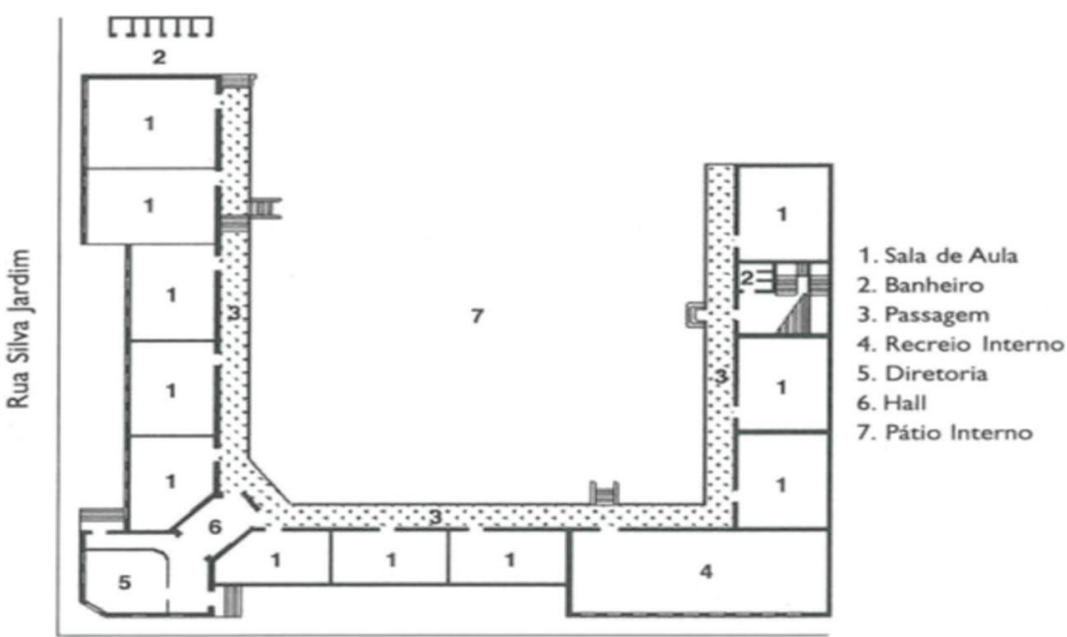

Rua Marechal Floriano Peixoto

Fonte: Secretaria de Administração do Paraná (BENCOSTTA, 2005).

Figura 2 - Planta Baixa da Escola Normal de São Paulo

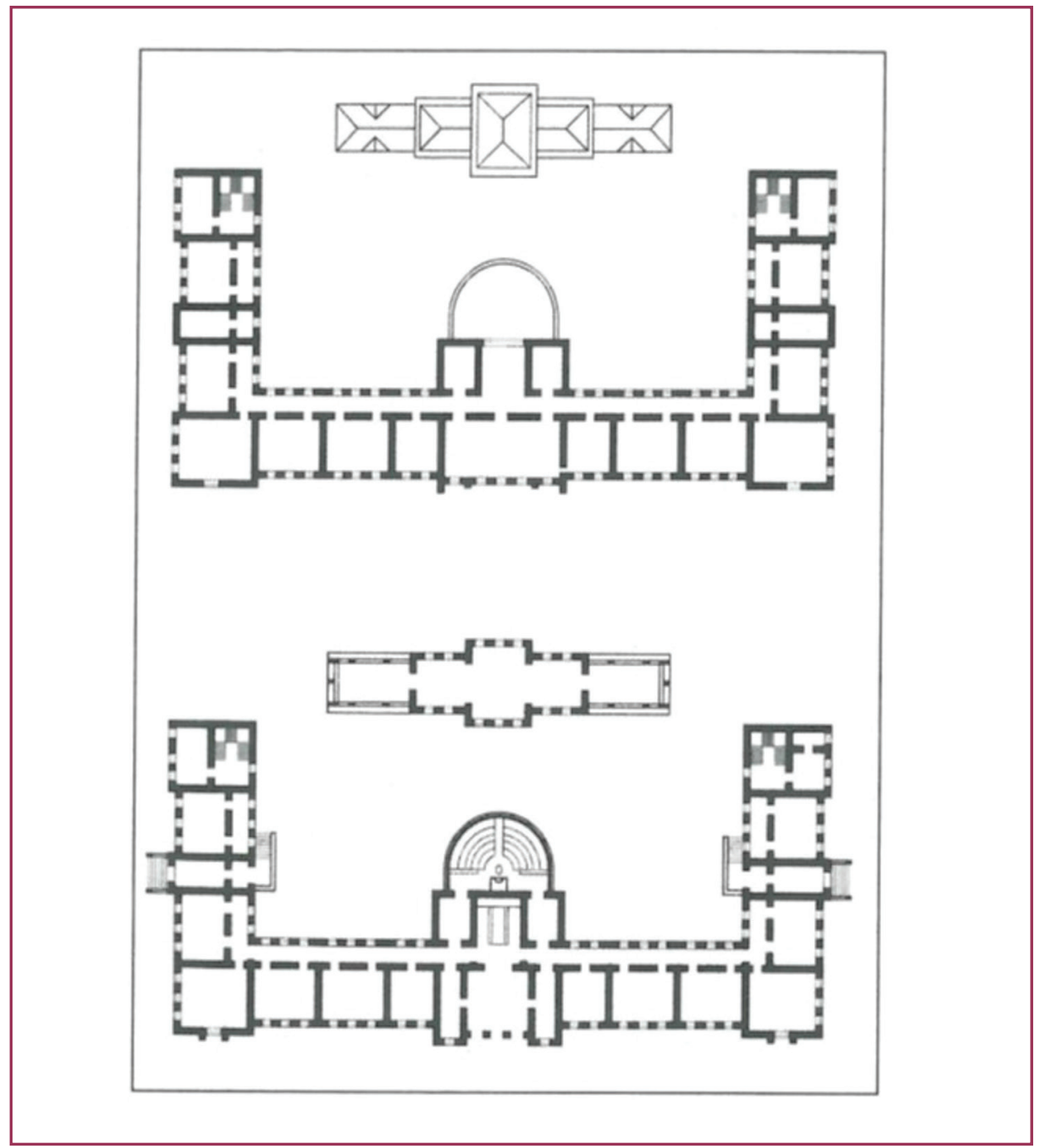

Fonte: Faculdade de Arquitetura e Urbanismo da USP (BENCOSTTA, 2007). 
Figura 3 - Planos de planta baixa do Grupo Escolar de "Grácia" em Barcelona (1921)

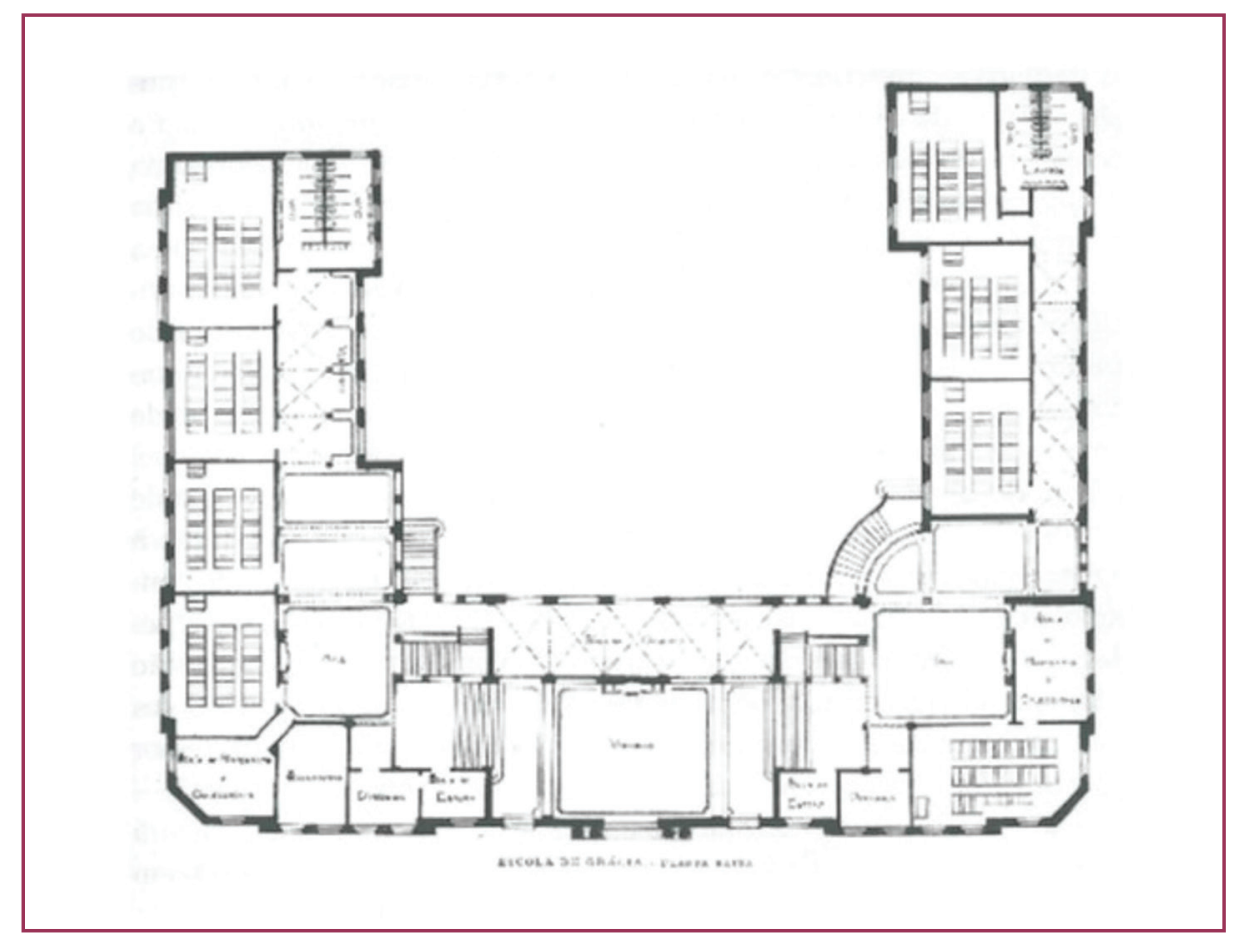

Fonte: VIÑAO (2005).

Figura 4 - Planta Baixa - Grupo Escolar de 4 classes em Minas Gerais

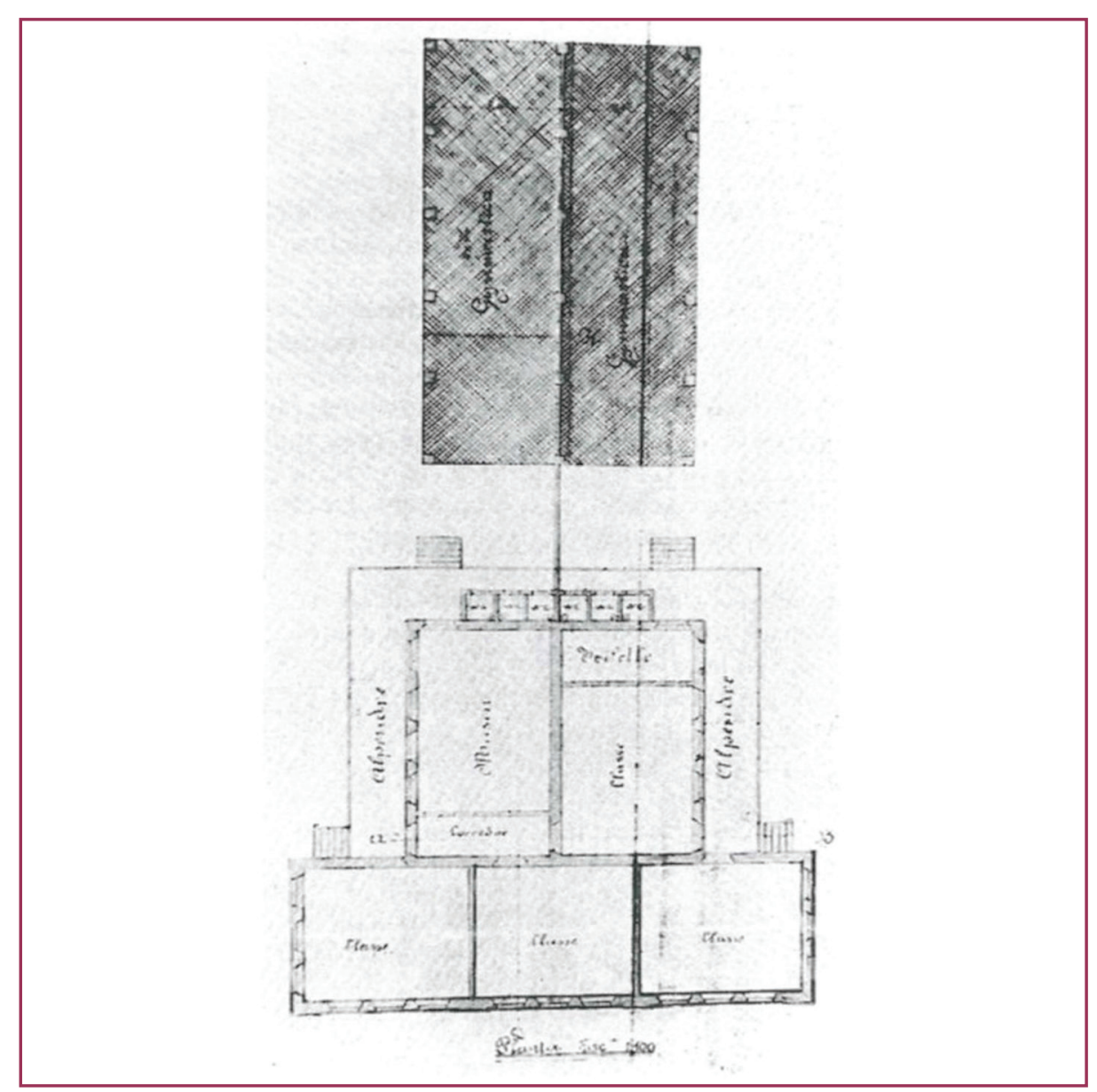

Fonte: Arquivo Público Mineiro (VAGO, 2002). 
De todo modo, segundo diferentes autores, se a arquitetura escolar favorecia a definição de espaços para a ginástica, era no ginásio onde os seus praticantes deveriam encontrar um ambiente melhor estruturado para a exercitação do corpo, não apenas pela disponibilidade de aparelhos, mas pelo auxílio de instrutores ou autoridades no assunto, podendo, com isso, praticar a ginástica racional preconizada na época.

Assim como a adequação das salas de aulas exigia alguns cuidados, os ginásios também deveriam ser adequadamente preparados para a realização dos exercícios. Isso refletiria, segundo os autores de manuais didáticos, na prática pedagógica do professor ou instrutor. Mas como eram os ginásios construídos ainda no século XIX? O que eles continham? Mapear exatamente como eram ordenados os ginásios não é tarefa fácil, mas é preciso lembrar que eram instalações erigidas com o fim precípuo de desenvolver atividades ginásticas. Ou seja, tratava-se, já, de uma especialização em relação àqueles outros espaços difusos, tais como o entorno das escolas, os pátios ou as salas de aula. Se consultarmos o inventário feito por Carl Hermann Schildbach sobre as instalações do ginásio dirigido por Schreber em Leipzig, é possível termos ao menos uma noção dos objetos ali abrigados. Consta na lista:

Quatro conjuntos de barras paralelas, três barras fixas, duas escadas de suspensão,
uma escada dorsal, uma escada de corda, um par de cordas de amarrar, um par
de anéis, uma plataforma giratória (descrita na Kinesiatrik), um grande parafuso
para os movimentos de manivela, dois cavalos com alças, sendo um estreito e alto
e o outro baixo e largo, ambos com um batente, uma escada espiral tipo Delpech,
um suspensor de Gilson, um extensos de Kunde de oito braços, um carrossel
de quatro raias, diversos halteres de diferentes pesos assim como bastões de
vários comprimentos. Além disso, há também (mas não para o uso ortopédico
logicamente) um par de barras de molas com cordas, um cavalo de alças para
acrobacias (ISRAËLS, 1986, p. 137)

Nota-se a existência de halteres e bastões, assim como de máquinas para trabalhar a musculatura do corpo. Nota-se também a presença de aparelhos bastante utilizados na realização de acrobacias, como o cavalo com alças, além das barras (fixa e paralelas) e do par de anéis. A produção, aquisição e circulação desses equipamentos têm muito a nos dizer sobre a cultura material produzida em decorrência do ensino e da prática da ginástica (seja na escola, seja fora dela).

Na documentação consultada na Escola Estadual Caetano de Campos, em São Paulo, localizamos uma foto do ginásio onde Baragiola (que citou Schreber em seu manual) trabalhava (foto 1). $O$ pórtico montado sobre o chão (forrado com areia) tinha duas escadas, cordas (lisa e de nós) e cabos. Nota-se a construção de janelas e duas "aberturas" em forma de arco nas laterais e outra ao fundo, possibilitando a entrada e circulação de ar, resguardando alguns dos princípios higiênicos para o desenvolvimento das aulas de ginástica. Nota-se ainda a aquisição de instrumentos como halteres e maças (lados direito e esquerdo da foto, respectivamente) ambos alocados em um suporte, além de um cavalo e uma espécie de trampolim, ao centro. Parte desses instrumentos e aparelhos foi mencionada no inventário do ginásio de Schreber, na Alemanha.

7 Traduzido do francês por Lincoln Heringer. 
Figura 5 - Ginásio da Escola Normal e anexas de São Paulo.

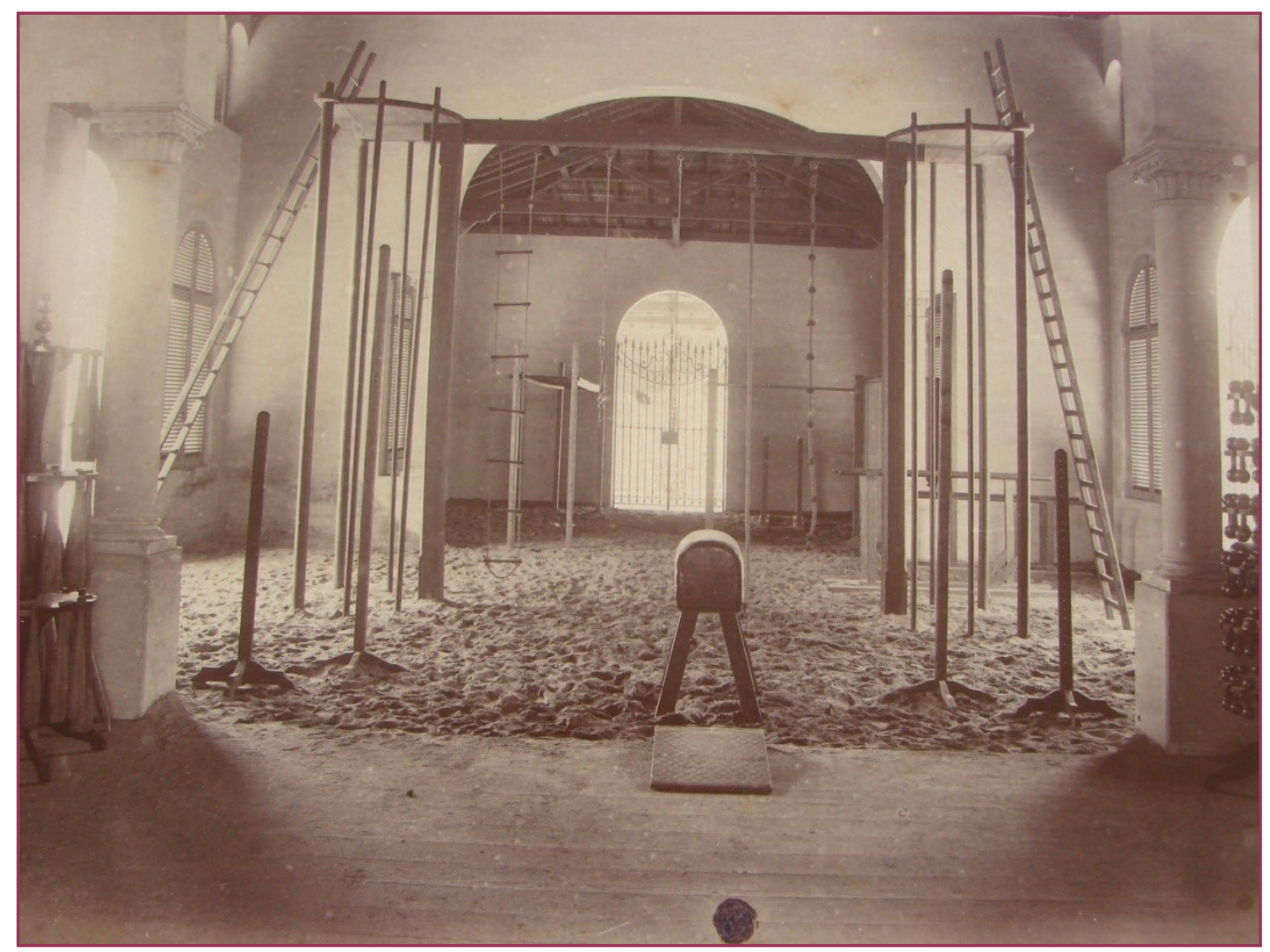

Fonte: Álbum fotográfico da Escola Normal - 1895. Acervo da Escola Estadual Caetano de Campos, São Paulo/SP.

No rol dos ambientes reivindicados para a ginástica e para a prática de exercícios físicos nas escolas, segundo os livros por nós investigados, o ginásio era o de menor incidência. Não sabemos exatamente os motivos. No entanto, não é difícil imaginar o porquê dessa situação em um país no qual até mesmo a presença dos grupos escolares não pode ser generalizada. Mas independentemente da sua universalização ou não, é notável como foi um espaço pensado e construído com uma finalidade clara, a educação dos corpos.

Provavelmente pelo grau de especialização que implicavam, com um uso muito restrito, aliado à falta de recursos para a sua construção e manutenção, eles não eram privilegiados nos orçamentos da instrução pública. 0 fato é que a construção de ginásios não foi levada adiante pelos governantes e a grande maioria das escolas ficou sem esse espaço para a realização da ginástica, embora a sua presença seja notada na Escola Caetano de Campos, acima citada, e no Colégio Estadual do Paraná, segundo o trabalho de Chaves Jr. (2004). Não por acaso escolas não destinadas ao conjunto da população, mas frequentadas por parcelas da classe média e pela elite.

Mas outras iniciativas pareciam ao menos almejar o espraiamento da ginástica pelas escolas brasileiras. Assim, entre os anos finais do século XIX e o começo do século XX, na ausência de espaços cobertos, e havendo tempo bom, era nos pátios de recreio que as crianças costumavam se exercitar. Espaço privilegiado dos folguedos infantis, os pátios também foram ocupados pela ginástica. Seguindo os preceitos de higiene, como os demais espaços escolares, "os pátios de recreio devem ser vastos, planos e perfeitamente limpos e arborizados" (SÃO PAULO 1904a, Art. 47 e 48; 1904b, Art. 44 e 45). De acordo com a legislação paulista, "haverá 
em cada pátio uma [área] coberta, onde possam os alunos abrigar-se nos dias cálidos ou chuvosos". Já em Minas Gerais,

\footnotetext{
Além do edifício principal, das varandas, salas e gabinetes (...), os prédios escolares deverão ter:

1ㅇ Um jardim, em que serão dadas as lições de agricultura e de botânica elementar; $2^{\circ}$ Uma área nivelada, macadamisada, e, si possível, asfaltada e coberta, para exercícios ginásticos e evoluções militares (MINAS GERAIS, 1911, Art. 179).
}

Além da preocupação quanto ao piso, áreas cobertas foram pensadas como ideal almejado para todas as escolas, mesmo que nem sempre (ou na maioria das vezes) isso fosse possível. Para os grupos escolares foram previstos ainda "pátios, com um ou mais pavilhões cobertos para recreios e exercícios físicos" (MINAS GERAIS, 1924, Art. 190).

No estado do Paraná, entre os requisitos externos que cada prédio escolar deveria contemplar, estavam previstos: "b) ter a casa no centro do terreno a ela destinado, o qual, limitado por muro ou gradil, terá área suficiente para conter os pátios de ginástica e recreio, lavabos, privadas, jardins, etc." (PARANÁ, 1915, Art. 173, p. 36 e 37; 1917, Art. 158, p. 52 e 53). Assim, ao redor da casa ou do prédio escolar, é que deveria situar o espaço ao ar livre destinado à exercitação física das crianças, seja nas aulas de ginástica, seja nos intervalos de recreio. Com a criação dos pátios de recreio, criou-se também um espaço de transição, separando a escola da rua (FARIA FILHO, 2000; VAGO, 2002), mas permitindo ali algo como a sua expansão para dentro do ambiente escolar. Além disso, não raro aqueles espaços destinados aos recreios eram também separados para o uso dos alunos conforme o sexo.

No Rio de Janeiro também foi prevista para as escolas primárias a construção de "um ginásio para exercícios físicos, um pátio para jogos e recreios, e um jardim preparado segundo preceitos pedagógicos" (RIO DE JANEIRO, 1890, Art. 9). No caso das escolas que não contassem com prédios próprios, "[dar-se-ia] preferência para prédios que [tivessem]: d) um pátio coberto ou saída bastante clara e arejada para o recreio" (RIO DE JANEIRO, 1920, Art. 51, alínea d).

Acreditamos que o incremento na projeção e construção de novos espaços escolares advém de uma série de fatores. Decorre da prática de investimentos estatais para a contrução de prédios escolares específicos - incluidos os investimentos para a implantação dos grupos escolares - até outros fatores inter-relacionados, como a ampliação do currículo (com a escolarização de novos saberes, muitos deles ligados à educação dos corpos, portanto, dos sentidos), e a incorporação de todo um arsenal inovador de materiais didático-pedagógicos (globos, cartazes, coleções, carteiras, cadernos, livros, museus, laboratórios etc. Isso sem contar os instrumentos e aparelhos de ginástica (barra fixa, barras paralelas, argolas, cavalos com alças, cordas, escadas, cavaletes, aparelhos para salto, halteres, maças, bastões, entre outros). Todos esses aspectos influenciaram na organização da escola primária, inclusive no que diz respeito à relação entre espaços e tempos escolares, na medida em que uns acabavam por influenciar e até mesmo determinar os outros.

\section{CONSIDERAÇÕES FINAIS}

Sabemos que a escolarização da ginástica, juntamente com a viabilização de um projeto de escolarização de massas, representou não apenas a resposta a um novo tipo de sensibilidade, mas a sua produção, como a definição de novos valores e costumes na virada dos oitocentos 
para o início do século XX. Exemplo disso pode ser verificado na mobilização dos tempos e dos espaços para a educação dos corpos das novas gerações, seja através de um conjunto de valências como aceleração, velocidade e movimento, ou ainda, como vimos, na própria definição de formas de contenção e enquadramento adequados aos imperativos pedagógicos e escolares. Em outras palavras, o que procuramos inferir aqui, nos valendo da ginástica como exemplo, a partir da análise dos manuais destinados ao seu ensino, atentos à norma legal que o fundamentava, foi justamente a produção de novas sensibilidades pela exploração dos sentidos estimulados através dos usos dos tempos e espaços escolares. Isso nos limites possíveis da análise da sua prescrição em manuais didáticos e na legislação educacional, logo, do conteúdo daqueles, mesmo quando aquelas dimensões não eram apresentadas como educativas. Não é demais lembrar que não nos lançamos à análise da materialidade dos manuais, tema por demais interessante e relevante, mas que em muito extrapolaria os propósitos deste texto. Mesmo as imagens por nós mobilizadas foram consideradas conteúdos dos livros, por mais que ocupassem uma função ilustrativa.

Portanto, ao privilegiarmos os manuais de ginástica no intuito de observar como o tempo e os espaços destinados aos exercícios ginásticos encontram-se ali definidos, vale destacar que é preciso considerar tais definições muito mais como prescrições do que como efetivação de práticas. O cotejamento do conteúdo dos livros com a legislação e os programas de ensino se deu justamente para que pudéssemos aferir a proximidade daquele com a realidade escolar. Mas ainda carecemos de pesquisas que tomem as práticas escolares como objeto historiográfico. Tanto em relação à ginástica quanto à Educação Física e demais componentes curriculares, muito há por fazer em relação a estudos que levam em conta a cultura material da escola e os seus efeitos sobre a educação dos corpos e das sensibilidades, tema promissor para pesquisas futuras, para as quais pretendemos contribuir com uma circunscrita análise das suas prescrições.

\section{REFERÊNCIAS}

BARAGIOLA, Manoel. Gymnastica nas aulas. Manual theorico-pratico. São Paulo: J. B. Endrizzi, 1895.

BENCOSTTA, Marcus Levy. Arquitetura e espaço escolar: o exemplo dos primeiros grupos escolares de Curitiba (1903-1928). In: BENCOSTTA, Marcus Levy A. (org.). História da educação, arquitetura e espaço escolar. São Paulo: Cortez, 2005. p. 95-140.

BENCOSTTA, Marcus Levy. Arquitetura Escolar na Belle Époque: Jean Omer Marchand e Francisco de Paula Ramos de Azevedo (Montreal e São Paulo, 1894-1926). In: BENCOSTTA, Marcus Levy (Org.). Culturas escolares, saberes e práticas educativas: itinerários históricos. São Paulo: Cortez, 2007. p. 103-128.

BORGES, Pedro M. Manual theorico-pratico de gymnastica escolar: elementar e superior. Rio de Janeiro: B. L. Garnier, 1888.

BRAGHINI, Katya; MUNAKATA, Kazumi; TABORDA DE OLIVEIRA, Marcus Aurelio (orgs.). Diálogos sobre a história da educação dos sentidos e das sensibilidades. Curitiba: Editora UFPR, 2017.

CABRAL, Pedro Luiz da Costa. A aliança dos contrários: a ginástica protagonizada no circo (Brasil, 1840 - 1880). 2016. 189 f. Dissertação (Mestrado em Educação) - Programa de Pós- 
Graduação em Educação: conhecimento e inclusão social, Universidade Federal de Minas Gerais, Belo Horizonte, 2016.

CALDAS, M.; CARVALHO, E. Manual de Gymnastica Escolar. Rio de Janeiro:Francisco Alves, 1896.

CAMPOS, Regina Helena F. História da Psicologia e História da Educação: conexões. In: FONSECA, Thais N. L.; GREIVE, Cynthia G. (orgs.). História e Historiografia da Educação no Brasil. Belo Horizonte: Autêntica, 2003. p. 129-158.

CAMPOS, Regina Helena F.; GOUVEA, Maria Cristina S.; GUIMARÃES, Paula Cristina D. A recepção da obra de Binet e dos testes psicométricos no Brasil: contrafaces de uma história. Revista Brasileira de História da Educação, v. 14, n. 2, p. 215-242, maio/ago. 2014.

CHAVES JUNIOR, Sérgio. A educação física do ginásio paranaense ao colégio estadual

do Paraná: contribuições para a construção de uma história de uma disciplina escolar (19311951). 2004. 228 f. Dissertação (Mestrado em Educação) - Programa de Pós-Graduação em Educação, Universidade Federal do Paraná, Curitiba, 2004.

ESCOLANO, Agustín. Tiempos y espacios para la escuela: ensayos históricos. Madrid: Editorial Biblioteca Nueva, 2000.

ESCOLANO, Agustín. La arquitectura como programa: espacio-escuela y curriculum. Revista Interuniversitaria Historia de la Educación, n. 12-13, p. 97-120, 1993/1994.

FARIA FILHO, Luciano Mendes. Dos pardieiros aos palácios: cultura escolar e urbana em Belo Horizonte na Primeira República. Passo Fundo: UPF, 2000.

FARIA FILHO, Luciano Mendes; VIDAL, Diana. Os tempos e os espaços escolares no processo de institucionalização da escola primária no Brasil. Revista Brasileira de Educação, n. 14, p. 19-34, maio/ago.2000.

GAY, Peter. A Educação dos Sentidos: a experiência burguesa da Rainha Vitória à Freud. São Paulo: Companhia das Letras, 1989.

HIGGINS, Arthur. Compendio de Gymnastica Escolar: methodo sueco-belga. Rio de Janeiro: Typ. Jornal do Commercio, 1909.

ISRAELS, Han. Schreber, père et fils. Paris: Éditions du Seuil, 1986.

KUMLIEN, L. C. Tratado Pratico de Gymnastica Sueca. Lisboa: Typographia Lusitana Editora, 1908.

MEDEIROS, Daniele Cristina; SOARES, Carmen Lucia. Uma natureza que educa: as estâncias hidrominerais no estado de São Paulo (1930-1940). Movimento, v. 23, n. 3, p. 949-962, 2017.

MELO, Victor A.; PERES, Fabio F. A Gymnastica no tempo do império. Rio de Janeiro: 7Letras, 2014.

MEURER, Sidmar dos Santos; TABORDA DE OLIVEIRA, Marcus Aurelio. A invenção dos recreios nas escolas primárias paranaenses: o lugar da educação do corpo, dos sentidos e das sensibilidades na escola. Revista Brasileira de Educação, v. 21, p. 225-247, 2016.

MINAS GERAIS. Decreto n. 6655, de 18 de agosto de 1924. Regulamento do ensino primário (para execução da lei n. 800, de 27/09/1920). Disponível em: https://www.almg.gov.br/consultel legislacao/completa/completa.html?tipo=DEC\&num=6655\&comp=\&ano=1924 Acesso em: 16 out. 2019 
MINAS GERAIS. Decreto n. 3191, de 9 de junho de 1911. Regulamento geral da instrução do Estado de Minas Gerais. Disponível em: https://www.almg.gov.br/consulte/legislacao/completa/ completa.html?tipo=DEC\&num=3191\&comp=\&ano=1911. Acesso em: 16 out. 2019.

MORENO, Andrea. A propósito de Ling, da ginástica sueca e da circulação de impressos em língua portuguesa. Revista Brasileira de Ciências do Esporte, v. 37, p. 128-135, 2015.

MORENO, Andrea. Educando corpos e sensibilidades: "não se descuide desta parte da educação das creanças na escola porque della depende o desenvolvimento physico dos futuros cidadãos". In: GONÇALVES NETO, Wenceslau; CARVALHO, Carlos Henrique de. (org.). História da Educação em Minas Gerais: da Colônia à Republica. Uberlândia: Edufu, 2019. v. 3, p. 55-74.

PARANÁ. Decreto n. 17 de 9 de janeiro de 1917. Código do Ensino. Disponível em: https:// repositorio.ufsc.br/xmlui/handle/123456789/125257. Acesso em: 16 out. 2019.

PARANÁ. Decreto n. 710 de 18 de outubro de 1915. Código do Ensino. Disponível em: https:// repositorio.ufsc.br/handle/123456789/99744. Acesso em: 16 out. 2019.

PUCHTA, Diogo. Homem Forte: uma história da Educação Física no estado do Paraná. Curitiba: Appris, 2019.

PUCHTA, Diogo. A escolarização dos exercícios físicos e os manuais de ginástica no processo de constituição da educação física como disciplina escolar (1882-1926). 2015. 286 f. Tese (Doutorado em Educação) - Programa de Pós-Graduação em Educação: conhecimento e inclusão social, Universidade Federal de Minas Gerais, Belo Horizonte, 2015.

QUITZAU, Evelize; SOARES, Carmen Lucia. Um manual do século XVIII: culto à natureza $e$ educação do corpo em "Ginástica para a Juventude", de Guts Muths. Revista Brasileira de História da Educação, v. 16, p. 23-50, 2016.

RIO DE JANEIRO. Decreto n. 1416 de 9 de abril de 1920. Dá Regimento Interno para as escolas públicas primárias do Distrito Federal. In: Boletim da Prefeitura do Distrito Federal. Rio de Janeiro: "Typ. do Jornal do Commercio", 1920.

RIO DE JANEIRO. Decreto $\mathrm{n} .981$ de 8 de novembro de 1890. Regulamento da instrução primária e secundária do Distrito Federal. Disponível em: https://www2.camara.leg.br/legin/fed/decret/1824-1899/ decreto-981-8-novembro-1890-515376-publicacaooriginal-1-pe.html. Acesso em: 16 out. 2019.

ROMÃO, Anna Luiza Ferreira. Entre escolas, clubs e sociedades: as Gymnasticas tecidas por professores no Rio de Janeiro (1850-1900). 2016. 199 f. Dissertação (Mestrado em Educação) - Programa de Pós-Graduação em Educação: conhecimento e inclusão social, Universidade Federal de Minas Gerais, Belo Horizonte, 2016.

SÃO PAULO. Decreto n. 1216, de 27 de abril de 1904a. Regimento Interno dos Grupos Escolares e Escolas Modelo. Disponível em: https://www.al.sp.gov.br/repositorio/legislacao/ decreto/1904/decreto-1216-27.04.1904.html. Acesso em: 16 out. 2019.

SÃO PAULO. Decreto n. 1253, de 28 de novembro de 1904b. Regimento Interno dos Grupos Escolares. Disponível em: http://www.al.sp.gov.br/repositorio/legislacao/decreto/1904/ decreto-1253-28.11.1904.html. Acesso em: 16 out. 2019.

SCHREBER, Daniel Moritz. Gymnastica doméstica, médica e higiênica. Lisboa: Candido Magalhães, [18--]. 
SOARES, Carmen Lúcia; MORENO, Andrea. Dossiê - Práticas e prescrições sobre o corpo: a dimensão educativa dos métodos ginásticos europeus. Revista Brasileira de Ciências do Esporte, v. 37, p. 108-110, 2015.

TABORDA DE OLIVEIRA, Marcus Aurelio (org.). Educação do corpo na escola brasileira. Campinas: Autores Associados, 2006.

TABORDA DE OLIVEIRA, Marcus Aurelio. Saberes e práticas sobre a educação do corpo infantil na instrução pública primária nos anos finais do século XIX no Brasil. Sarmiento (Vigo), v. 13, p. 131-150, 2009.

TABORDA DE OLIVEIRA, Marcus Aurelio (org.). Sentidos e sensibilidades: sua educação na história. Curitiba: Editora UFPR, 2012.

TABORDA DE OLIVEIRA, Marcus Aurelio; LINHALES, Meily Assbú. Pensar a educação do corpo na e para a escola: indícios no debate educacional brasileiro (1882-1927). Revista Brasileira de Educação, v. 16, p. 389-407, 2011.

THOMPSON, Edward. Costumes em comum. São Paulo: Companhia das Letras, 1998.

VAGO, Tarcísio Mauro. Das escrituras à escola pública: A Educação Física nas séries iniciais do ensino fundamental. In: SOUZA, Eustáquia Salvadora de; VAGO, Tarcísio Mauro. Trilhas e partilhas. Belo Horizonte: Edição dos autores, 1997, p. 59-93.

VAGO, Tarcísio Mauro. Cultura escolar e cultivo de corpos: Educação Physica e Gymnastica como práticas constitutivas dos corpos de crianças no ensino público primário de Belo Horizonte (1906-1920). Bragança Paulista: EDUSF, 2002.

VIÑAO, Antonio. Espacio y tiempo, educación e historia. Morelia: IMCED, 1996.

VIÑAO, Antonio. Del espacio escolar y la escuela como lugar: propuestas y cuestiones. Revista Interuniversitaria Historia de la Educación, n. 12-13, p. 17-74, 1993/1994.

VIÑAO, Antonio. Espaços, usos e funções: a localização e disposição física da direção escolar na escola graduada. In: BENCOSTTA, Marcus Levy A. (org.). História da educação, arquitetura e espaço escolar. São Paulo: Cortez, 2005. p. 15-47.

WILLIAMS, Raymond. La larga revolución. Buenos Aires: Nueva Visión, 2003.

Apoio:

CNPq n. 409171/2018-2, Edital Universal e da Coordenação de Aperfeiçoamento de Pessoal de Nível Superior - Brasil (CAPES) - Código de Financiamento 001. This study was financed in part by the Coordenação de Aperfeiçoamento de Pessoal de Nível Superior - Brasil (CAPES) - Finance Code 001. 